\title{
Catriona Seth, André Chénier, Le Miracle du siècle
}

\section{Patricia Ménissier}

\section{(2) OpenEdition}

\section{Journals}

Édition électronique

URL : https://journals.openedition.org/studifrancesi/26443

DOI : $10.4000 /$ studifrancesi.26443

ISSN : 2421-5856

\section{Éditeur}

Rosenberg \& Sellier

\section{Édition imprimée}

Date de publication : 1 avril 2007

Pagination : 187-188

ISSN : 0039-2944

\section{Référence électronique}

Patricia Ménissier, «Catriona Seth, André Chénier, Le Miracle du siècle », Studi Francesi [En ligne], 151

(LI | I) | 2007, mis en ligne le 30 novembre 2015, consulté le 23 novembre 2021. URL : http://

journals.openedition.org/studifrancesi/26443; DOI : https://doi.org/10.4000/studifrancesi.26443

\section{Ce document a été généré automatiquement le 23 novembre 2021.}

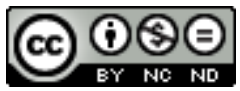

Studi Francesi è distribuita con Licenza Creative Commons Attribuzione - Non commerciale - Non opere derivate 4.0 Internazionale. 


\title{
Catriona Seth, André Chénier, Le Miracle du siècle
}

\author{
Patricia Ménissier
}

\section{RÉFÉRENCE}

CATRIONA SETH, ANDRÉ CHÉNIER, Le Miracle du siècle, Paris, Presses de l'Université Paris-

Sorbonne, «Mémoire de la critique», 2005, pp. 350.

1 L'ouvrage que Catriona Seth livre aux Presses de l'Université de Paris-Sorbonne constitue un complément presque nécessaire à la lecture des œuvres en cours de réédition d'André Chénier (par Georges Buisson et Édouard Guitton, qui ont livré en 2005, aux Éditions Paradigme, le premier tome de ses (Euvres poétiques). Il propose en effet au lecteur de revenir sur la fortune littéraire d'une œuvre privée de son auteur et, ce faisant, de saisir tout à la fois la réception d'un poète et les préoccupations politiques ou littéraires du XIX ${ }^{\mathrm{e}}$ siècle qui l'a reconnu.

2 Conçu comme une anthologie d'articles, d'extraits épistolaires ou romanesques, les documents sont livrés chronologiquement. Le lecteur pourra saisir l'évolution des mentalités et des conceptions littéraires sur Chénier, en adoptant une lecture suivie ou choisir une perspective thématique pour retrouver, par exemple, le point de vue des éditeurs du «fier André» (Latouche, mais aussi Becq de Foucquières, Gabriel de Chénier, le neveu du poète, ou encore Heredia à propos du manuscrit des Bucoliques) ou le regard des poètes, de Hugo à Heredia en passant par Leconte de Lisle, Vigny, Gautier et Régnier. Même si tous les textes du critique ne figurent pas dans le recueil, on pourra également aborder la réflexion de Sainte-Beuve qui, ébloui par sa découverte des manuscrits du poète, ne cessera plus de s'interroger, à l'instar de ses contemporains, sur la place d'André Chénier dans l'histoire de la littérature. L'ensemble des documents est précédé d'une préface, qui revient sur les étapes de la réception du poète en apportant des témoignages et des documents supplémentaires, que la forme de l'anthologie ne pouvait prendre en charge. Des notices, en fin d'ouvrage, offrent très 
opportunément la possibilité de situer l'un ou l'autre de ceux qui se sont intéressés à Chénier et à son œuvre.

3 Les deux premiers témoignages recensés par Catriona Seth ont été livrés du vivant d'André Chénier, lorsque, pour le public du XviII ${ }^{e}$ siècle, il n'était que le frère de MarieJoseph. La notice favorable de Charles Palissot et l'épître élogieuse du poète, PonceDenis Écouchard-Lebrun, deux de ses intimes, ne rencontrent donc pas l'opinion du temps. Comme l'écrit Leconte de Lisle, dans La Variété en août 1840, «André, en montant à l'échafaud, savait seul qu'un grand poète allait mourir». Hormis la notice remaniée que Palissot livre en 1803, c'est en réalité la première édition de ses œuvres par Henri de Latouche en 1819 qui permet de faire naître André Chénier à son destin posthume. Le poète se présente alors, selon l'expression de Jean-Baptiste Amar-Durivier, «sous le double aspect d'homme de lettres et de personnage historique» (p. 74).

Beaucoup reviennent de fait sur le destin de ce poète «novateur secret et ignoré, qui fit sa révolution pour lui seul» (Saint-Marc Girardin, p. 199), disparu dans la tourmente de l'histoire, adoptant une perspective biographique qui les conduit à évoquer ses relations avec Marie-Joseph. Quelques textes s'intéressent à la prose politique d'André Chénier, principalement lorsque l'actualité, comme en 1848, amène à faire un parallèle avec la Révolution de 1789. Certains font remarquer les vues philosophiques et morales du poète pour s'en féliciter ou souligner l'absence de regard chrétien de ce «païen aimable» (Sainte-Beuve, p. 143).

Dans la première moitié du siècle, l'édition de Latouche soulève surtout le problème éditorial de l'inachèvement de l'œuvre d'un poète qui, selon Hugo, n'a pas eu le temps de devenir parfait: faut-il tout publier en vertu des beautés «éparses mais éclatantes» que relève Népomucène Lemercier (p. 189)? Charles Loyson refuse de lire les ébauches, mais François Raynouard plaide pour une publication intégrale. La question restera longtemps d'actualité. Face à cette œuvre fragmentaire, l'attention se porte surtout sur le génie antique du poète, le «tour simple et naïf de la pensée antique» (Jean-Baptiste Amar-Durivier, p. 75), à la mode duquel André Chénier aurait succombé selon Hugo, qui n'en note pas moins qu'il imite en maître, mais souligne surtout qu'il sera regardé «comme le père et le modèle de la véritable élégie» (p. 126). De fait, les commentateurs relèvent la qualité de l'âme du poète dans ses vers (Lebrun déjà en 1792, puis le Journal de Paris en 1819, Jules Lefèvre en 1823, Pierre-François Tissot en 1834 ou encore SaintMarc Girardin en 1843). En 1845, cependant, Arsène Houssaye conteste que le cœur soit seul poète dans les élégies de Chénier pour conclure que sa poésie «n'est pas un battement de cœur» (p. 206). Tous s'accordent néanmoins à reconnaître le coloris, le pittoresque de ses tours et expressions, la force de ses images, au point d'en faire, selon Blanchemain, un «amant de la forme. Chez lui, tout prend un corps, une âme, un esprit, un visage» (p. 194). La critique se divise encore au moment d'évoquer la versification du poète: toutes les lois du rythme sont «violées» à dessein selon Charles Loyson, qui parle de «déplorable et facile hardiesse» (p. 108), tandis que Hugo ou Raynouard notent que ces défauts, quoique grands, laissent place à d'heureux effets d'harmonie.

6 Le parcours que retrace André Chénier. Le Miracle du siècle conduit ainsi à légitimer la redécouverte d'un poète qui n'a pas fini d'interroger le lecteur, conformément à l'affirmation de Hugo dans Le Conservateur littéraire, dès 1819: «Il n'y aura point d'opinion mixte sur André Chénier. Il faut jeter le livre ou se résoudre à le relire souvent». À ceux qui souhaiteront découvrir la sensibilité poétique de Chénier, les 
documents qu'a recueillis Catriona Seth donneront la possibilité de multiplier les regards et les relectures sur une œuvre qui, plus que jamais, s'offre en pleine lumière. 